\title{
Break Through the Adversity: The Random Innovation Mode of Taiwan Sanli TV Station
}

Yulong Tu

School of Social and Public Administration, Lingnan Normal University, Zhanjiang, Guangdong, China

Article History
Received: 15.08 .2020
Accepted: 01.09 .2020
Published: 10.092020
Journal homepage:
ww.easpublisher.com/easjebm

Quick Response Code

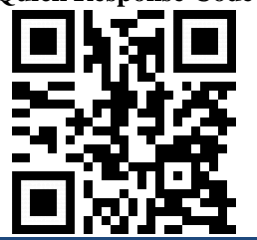

Abstract: In the process of development, the enterprises will inevitably encounter the constraints of insufficient resources and policies, which make them, enter the development dilemma. In the face of many resource shortages and policy restrictions, Taiwan Sanli TV station uses random innovation to reorganize limited resources, and turns resource constraints into the driving force of the enterprise development, so that the enterprise can break through the dilemma and win competitiveness.

Keywords: Resource At Hand, Making Do, Resource Reconstruction, Taiwan Sanli TV Station.

Copyright @ 2020: This is an open-access article distributed under the terms of the Creative Commons Attribution license which permits unrestricted use, distribution, and reproduction in any medium for non-commercial use (Non-Commercial or CC-BY-NC) provided the original author and source are credited.

\section{SUMMARY}

Random innovation is a concept proposed by French anthropologist Claude Levi-Strauss in his book The Savage Mind. He observed how artisans improvise, like piecing together discarded planks and scattered chair legs into stylish bookcases. This kind of random patchwork ability, similar to the survival in the wild, is random innovation. Craftsmen do not rely on precise calculation or rational analysis to carry out their work, but play spontaneously in the face of difficulties. As if tapping into primitive survival instincts in the wild, Levi-Strauss calls these bricoleur savage minds. This provides a new perspective for an organization facing resource shortage or many restrictions to still use and reorganize the limited resources at hand and build new opportunities. Successful innovation can help an enterprise to transform resource constraints into the driving force for its development, so that it can break through to win competitiveness against the trend.

\section{Three characteristics of random innovation:}

1.1 To use resource at hand. Levi-strauss (1968) advocated that the core spirit of the concept of spontaneity is to use all available and existing resources to recombine resources by using local materials to cope with the changes in the surrounding environment.

\section{Making do}

Levi-strauss (1968) described casualness as making do with whatever you have at hand.

\section{Recombination of resources for new purposes}

Using the existing things at hand to run the resource combination, and under the existing time, the uneven tools and materials are constantly combined through random innovation, and a new look appears under the change of methods and materials.

\section{Case Background: Taiwan SANLi TV Station}

Taiwan Sanli TV Station (hereinafter referred to as Sanli), formerly known as Sanli Film and Television Co., Ltd. established in May 1983, is a family enterprise of the Lin Kunhai family. It started its career in Kaohsiung and is famous for producing and distributing video tapes of TV programs. After entering into the field of TV channels in 1993, it changed its business to satellite TV channels. It is headquartered in Neihu District, Taipei city. In terms of the scale of Taiwan TV station, the scale of radio TV station is the largest, and in terms of drama production costs, Sanli will also have a large gap with the radio station. In addition, due to regional economic development and policy and other factors, Sanli is faced with huge market competition pressure, and the competitive 
resources in its hands are also limited. Specifically, there are three aspects of resource constraints: the first, the talents shortage: including a-list actors, scriptwriting talents and supporting actors; the second is lack of funds: including the lack of homemade drama fund, the lack of actor training fund; the third, the low level of profitability, intense market competition, and the dilution of ratings affect advertising revenue.

\section{HOW TO MAKE USE OF THE RESTRICTION OF RESOURCES AS THE DRIVING FORCE OF DEVELOPMENT \\ Resource reconfiguration \\ To search for beautiful models to fill the gap of a-list actors \\ Sanli owns eight channels and produces its} own drama and variety shows. The exposure of its actors is not a problem. However, due to the opportunities and favorable conditions provided by the mainland film and television market, Taiwanese artists have fled to the mainland for development. A high ratings of the idol drama is the most critical factor of the leading actor and actress, namely the industry known as the male and female first. The successful drama model in the past was that the leading actor and actress were performed by the first-line actors, supplemented by the second-line actors, and finally the third-line actors acted as supporting actors to enrich the plot, which was the guarantee of the audience rating and box office. A-listers must be in good shape and undergo rigorous theatrical training, while it takes years and huge amounts of money for television stations to get actors to play before they can be cast. In the early days, Taiwan's TV stations devoted themselves to cultivating a-listers and restricted a-listers from performing on brother stations. From 2008 to 2015 , the film and television industry in the Mainland rose rapidly, providing entertainers with remuneration five times higher than that in Taiwan. Moreover, the huge demand for actors and actresses in the Mainland ensured the entertainers' performance schedule. Taiwan's theater production rate has plummeted, and artists often finish one play without knowing when the next one will be. Sanli break the conventional thinking, looking for beautiful appearance, learn to play fast model to play the leading role of men and women, with high appearance level instead of superb acting. Many of the most popular artists, such as Chen QE, Cheng YC, Ruan JT, are in Sanli from model to become an a-list actor.

To build a talent platform for talent show writers and create a collective drama with senior writers

Drama production talent is the most important than the scriptwriter, is the key to determine the quality of the finished product. In the past, the production company has got a variety of expertise, and the most need rely on the lone hero to complete the scriptwriting work. However, due to low production cost, it is difficult to produce high-quality works, and the mainland market capacity is large, many senior editors to the mainland development, now the market only exists sporadic senior scriptwriter. Sanli has found that there are many young writers on the internet who expect their work to be discovered, Such as high ratings Harem Zhen Huan biography from the network writer Liu Lianzi. Sanli believes that network writers and senior scriptwriters can be used to put together a collective drama. Through the establishment of a scriptwriter selection platform to explore scriptwriter talent, and then Sanli immediately formed a network writers community, to provide scholarships to keen scriptwriter students for free tuition. At the end of the class, the studsent are chosen from each class: those who can write original content; the other is less original, but with strong executive ability, and includes them in the writing team. The senior scriptwriter and the new scriptwriter are invited to jointly create the script in the way of master and apprentice. The senior scriptwriter and the novice scriptwriter with high originality create the original script. The senior scriptwriter will modify again the play according to the viewing situation and emergency to ensure the audience rating.

\section{MAKING DO}

Senior second-line actors instructing the lead roles to reduce the actor training cost

When it came time to start filming, the models chosen for the lead roles had little time to train. Sanli's practice is that senior second-line actors are responsible for the play. In the past, Sanli started its business with restaurant shows and popular dramas. These actors grew up together with Sanli and have more than 10 years of acting experience. Although they are not popular a-list actors, they are good at acting skills and are important cast members in idol dramas. Senior secondary actors guide the models acting. This kind of opportunity also provides the senondary actors another stage to continue their career. That for the models is a rare opportunity to play with the predecessors, which can reduce their barriers across the full drama. The way that the senior secondary actors are responsible for the play, can not only speed up the progress of the leading role into the play, keep the quality of the play stable, but reduce the training costs for the actors. Some models often shot to fame after acting a play, and went the mainland to develoe immediately. The contract stipulates the film quantity for the actors in 3 years, 3 plays commonly. That cannot raise quotation even the popular actors, and also not worry about the leading role to walk out suddenly. The contract mode allows sanli to stabilize the performance cost of the three plays, more can accumulate the popularity for the protagonists, and make the acting gradually improve. At the end of the play, the model is not worried about being tied down, and Sanli can avoid the risk of using the wrong actor. 
To move from single channels to multiple channels, targeting niche market

Taiwan's market capacity is small, but more than 200 TV stations, coupled with the prevalence of new media, and the audience ratings have been seriously diluted. In order to overcome this restriction, Sanli adopted three approaches: first, to add channels to absorb advertising traffic. Taiwan's advertising volume changes significantly during the off-peak season. During the election period and the product season, there will be an explosion of TV advertising, and a single channel cannot absorb a large amount of advertising demand. Sanli gradually developed the multi-channel model, and opened Sanli Entertainment channel in 1993, Sanli Metropolis Channel in 1995, Sanli Drama Channel in 1996, Sanli News Channel in 1998, Sanli International Channel in 2000, and Sanli Bay channel and Financial Channel later. These new channels target different niches. For example, Sanli TV focuses on idol dramas and Chinese dramas. Sanli Taiwan broadcasts local dramas that sound like Hokkien. The three-way multi-channel strategy forms a new business model that allows advertisers to broadcast continuously through the multi-channel mechanism, making advertisers feel that excellent quality and reasonable price that can absorb more advertising volume. The content of a single channel is limited, so advertisers often compete for prime time. Multiple channels can increase customer choice, increase more the chance of artists show exposure, and practice the actors a variety of performance skills.

\section{To USE Local Materials}

To set up the art academy and reserve supporting actor talent

There is a group of indispensable supporting actors in the drama, although you can casually hire some extras, performance costs are low, but if the supporting actors lead to NG remake, will also delay the production schedule, thus increase production cost. As for the reduced production cost, only controlling the performance quality of these supportig actors can achieve the goal of reduced production cost, which is also a great dilemma in sanli's production. Sanli finds that there are many young people in Taiwan who are pursuing the dream of becoming a star. They are suffering from the lack of performance opportunities due to the limitation of appearance or other reasons. In 2012 Sanli set up the art academy cooperated with Huagang Industrial Foundation. The course includes six weeks, a total of 36 hours of study, a two classes, each class of about 40 people. The course is given priority to performances, such as physical training, the imitation, role analysis interpretation, imagination and improvisation, image performance. The tuition fee is about NT\$8000. Outstanding students can get the opportunity to perform in supporting roles. For example, in 2013's Delicious Miss, several supporting roles are directly selected from the graduating students. Sanli set up a reserve talent pool of extras by the art academy to ensure the performance level and free the production team from worries.

\section{To cooperate with competitors}

According to Taiwan's National

Communication Commission (NCC), Taiwan's TV stations must broadcast at least 20 percent of the domestically produced dramas. There are more than 200 televisions for 23 million population in Taiwan. With the growing emergence of new media, the television advertising revenues caused by the lack of adequate homemade drama funds, and to increase the production cost. The television station must find a new way. The practice of many stations is not to make good works for lack of production cost, but buy ready-made foreign plays to broadcast. Sanli finds that if it can cooperate with the brother alliance production department, not only can let brother televiosion station conform to the stipulations of the NCC, but can earn money, which can share the high homemade drama cost. If an idol drama can be broardcast several times, that can accumulate the different time ratings, and the ratings boost can lead to increase advertising revenue, thereby increase the television station revenues. Therefore, the strategy of Sanli in the subsequent production of new dramas is to sell the premiere right to radio stations, which can obtain a high premiere income, and then broadcast them in six channels of Sanli to earn advertising income, and finally sell them to brother cable stations to earn copyright revenue.

\section{The key factors of random innovation}

Gather information to understand the challenges, frame the problems, and find the relevance of limited resources.

Before finding solutions to the problems, Sanli can collect as much information as possible and list all possible solutions. At this stage, Sanli can think about how to combine resources with innovation and reuse existing resources in new ways. In this diffusion thinking Sanli can help the enterprise get rid of the framework and restrictions to find the relevence among limited resources at hand, such as missing a-list actors, but has experienced secondary actors, insufficient funds in training a-list actors, but with eight channels to provide exposure to actors. Sanli acutely recognized these new values of the limited resources, break the routine technique for training a-list actors throuth beautiful models that attract audience attention with senior secondary actors instructing, which can reduce training costs. These models participate the variety home-made shows. That can improve the actors'visibility, and enter a-line cast. Therefore, the resource constraints encountered are not avoiding problems, but analyzing the resources at hand and building opportunities. Random innovation is not a linear process, but a process of continuous diffusion and convergence thinking. 
To actively participate in problems and opportunities to create new possibilities

The premise of random innovation theory is to solve problems in the case of insufficient resources. Making do with is an important element, and it is necessary to make do with the resources at hand to create new values. The basic principle of spontaneity is to make the best use of whatever resources are available. Taiwan itself has a small market capacity, but it has more than $200 \mathrm{TV}$ stations and competition from new media. Its audience rating is diluted. Sanli has a conservative investment route, low debt ratio and does not engage in high-risk financial leverage operations. If there is a surplus each year, the most of porfit is reserved for the addition of channels that gradually increases from a single channel to eight channels in order to target different groups. Then the compound effect of advertising among these channels can increase the revenue. In the process of making use of it, Sanli does not avoid problems, but actively participates in problems and searches opportunities. Unexpected results appear in the process of trial and error, thus creating new possibilities.
To emphasize the integration and reuse of resources to extend the limited resources

Since resources are limited, it is more appropriate to combine resources at hand for new goals. Composition includes the innovation of new purposes by combining different resources, as well as the redefinition of the use of resources, giving new ways of application and reuse. When faced with a shortage of drama production fee, wireless television and cable TV are competitors from the point of the local market, Sanli can intergrate the opponent resource. First Sanli took the premieres to radio station when new shows were released recycling one third to half of the production cost. Second Sanli carried out the second broadcast after a week earning advertising revenue. Finally Sanli found cable television, such as the television station, granted the rights to a third broadcast, and obtains the income for the authorization. This kind of resource integration and reusing breaks the general definition of the resource, taking advantage of seemingly inadequate resources, but can integrate the competitors resource, which can extend limited resources and overturn imposed limits.

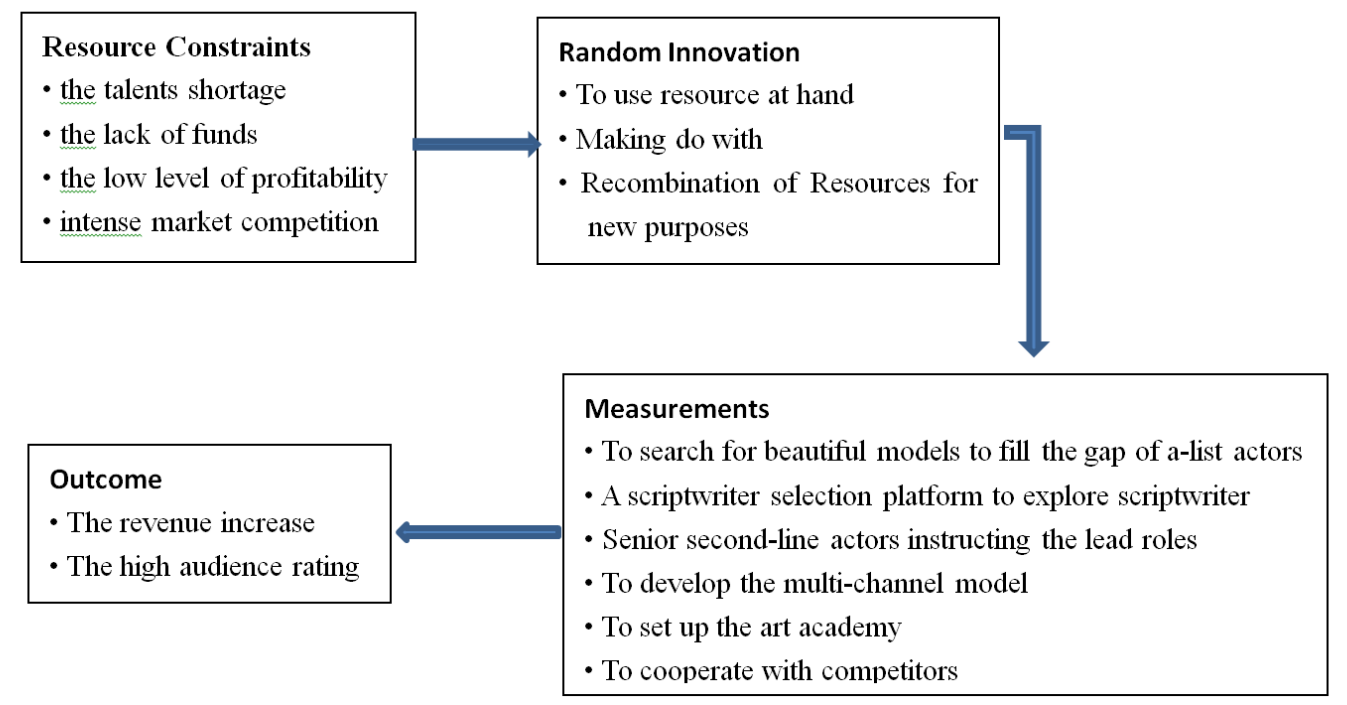

Figure 1 The random innovation mode of Sanli

\section{The Outcome of Random Innovation}

Sanli's random innovation mode (as shown in Figure 1) makes sanli better than its competitors in many indicators in the subsequent development, and it performs well in financial performance. The advertising revenue of general cable TV stations accounts for about $50 \%$ of the total revenue, while the advertising revenue of Sanli accounts for $65 \%$. The licensing revenue is about $15 \%$ 20\% of the revenue, and the system revenue is $20 \%$ of the revenue. Not only did Sanli continue to rise in ratings, its revenue doubled from NT\$ 2 billion in 2000 to NT\$ 4 billion in 2005. In 2011 the revenue jumped to NT\$ 4.953 billion. The revenue increased to NT\$ 5.429 billion in 2012. In 2013 it was NT\$ 5.732 billion. The high audience rating of idol drama and financial performance of Sanli also reflect the effect of random innovation. The key elemet is the collection of data opposite the trend, the active participation in problems and opportunities, and the emphasis on the integration and reuse of resources. Only in this way can a series of random innovation behaviors be successfully completed: resource reconstruction and making use of them.

\section{REFERENCES}

1. Baker, T., Miner, A. S., \& Eesley, D. T. (2003). Improvising firms: Bricolage, account giving and improvisational competencies in the founding process. Research policy, 32(2), 255-276.

2. Grant, A.M. (2012). Leading with meaning:beneficiary contact, prosocial impact, and 
the performance effects of transformational leadership. Academy of Management Journal, 55(2), 458-476.

3. Guang, T., Trotter, D., \& Yu, L. (2015). Anthropological methods are meaningful in business research: A case study of foodservice at a Chinese University. The Anthropologist, 19(1), 211-227.

4. Levi-Strauss, C. (1968). The Savage Mind, 1st, Chicago: University of Chicago Press.

5. Tu, Y.L. (2019). Enterprise platform management: new growth opportunities for enterpAdrises, East
African Scholars Journal of Economics, Business and Management, 9(2), 658-662.

6. Wang, S., Tu, Y., \& Liu, S. (2014). The evolution of state-owned enterprises in South China: The choice of property right system perspective. The Anthropologist, 18(1), 103-111.

7. Wang, S.J. (2015). Field research on business culture evolution path and influence on performance: The perspective of Business Anthropology, Journal of Shanxi University of Finance and Economics, 37(3),72-84. 